\title{
Percepções de adolescentes sobre sexualidade e educação sexual
}

\author{
Adriana Rodrigues $\mathrm{ZOCCA}^{1}$ \\ Luci Regina MUZZETI ${ }^{2}$ \\ Natália Souza NOGUEIRA ${ }^{3}$ \\ Paulo Rennes Marçal RIBEIRO ${ }^{4}$
}

\section{Introdução}

Nem sempre é fácil falar sobre sexualidade e educação sexual, deste modo, como será que os adolescentes compreendem e lidam com a temática? Este texto tem por objetivo desvelar alguns aspectos sobre a temática na ótica dos jovens.

Inicialmente vale lembrar que a adolecência é um período de transformaçóes e de transição entre a infância e a vida adulta. Nesse momento, a construção do futuro ocorre mediante uma diversidade de possibilidades e escolhas, o grupo de amigos, os valores, a experiência e a experimentação de novos papéis. É nessa fase que a identidade do eu e a identidade pessoal estáo ligadas à história de

$\overline{1}$ Mestre em Educação Sexual. UNESP - Universidade Estadual Paulista. Faculdade de Ciências e Letras - Pós-Graduação em Educação Sexual. Araraquara - SP - Brasil. 14800-901 - adriana.zocca@gmail.com

2 UNESP - Universidade Estadual Paulista. Faculdade de Ciências e Letras - Professora do Programa de Pós-Graduação em Educação Sexual. Araraquara - SP - Brasil. 14800-901-lucirm@fclar.unesp.br

3 Mestre em Educação Sexual. UNESP - Universidade Estadual Paulista. Faculdade de Ciências e Letras - Pós-Graduação em Educação Sexual. Araraquara - SP - Brasil. 14800-901 - nogueiranc@ig.com.br

4 UNESP - Universidade Estadual Paulista. Faculdade de Ciências e Letras - Professor do Programa de Pós-Graduação em Educação Sexual. Araraquara - SP - Brasil. 14800-901 - paulorennes@fclar.unesp.br 
vida do adolescente e o proporciona um entendimento das vivencias passadas e o enfrentamento de novos desafios do presente e do futuro (FIERRO, 1995).

Neste contexto de mudanças para o adolescente, muitas são as preocupaçóes, entre elas, gravidez indesejada, doenças sexualmente transmissíveis, o uso adequado de preservativos, conhecimentos sobre o corpo, a iniciação das relaçóes sexuais imaturamente, masturbação, uso de contraceptivos, entre outras. Por isso, a educação sexual é imprescindível, principalmente neste momento da vida, onde as transformaçóes e novidades são vivenciadas ao lado das dúvidas e incertezas.

A sexualidade é inerente ao ser humano, vital durante todo o nosso ciclo de vida e interligada as práticas sexuais, sentimentos, afetividade, desejos, prazer e a saúde. A sexualidade se transforma ao longo do tempo acompanhando as necessidades da época, com mitos, tabus e relaçóes de poder. Portanto, é necessário que a educação sexual seja contextualizada de maneira dinâmica e ao mesmo tempo sistemática para atender a todos os espaços vagos que permanecem na cabeça dos adolescentes.

Os pais têm demonstrado dificuldade em abordar esse assunto com naturalidade, passando a responsabilidade, muitas vezes, à escola e aos profissionais da saúde (médico, enfermeiro e psicólogo), pois se sentem despreparados, tendo como consequência um adolescente desassistido.

Ao lado disso, Pacheco (2008) nos revela o luto que os pais vivenciam pela perda do filho criança que os remete a própria percepção do envelhecimento. Deste modo, os pais se tornam facilitadores nesse momento de transiçáo que os filhos vivenciam, se estão preparados e resolvidos para isso. É importante destacar que os pais tanto quanto os professores precisam lidar de maneira tranquila com suas sexualidades para conseguem refletir sobre o assunto, saber o momento de dialogar, argumentar, escutar, e procurar artefatos para sanar toda essas questóes de seus filhos ou alunos.

Diante disso, há dois tipos de educação sexual, a informal e a formal. Essa última diz respeito a todo ensino intencional e planejado, sobre a sexualidade feita na escola, enquanto que a informal está presente no cotidiano e também educa. É captando uma mensagem aqui e outra acolá, uma fala, um olhar, um riso saudável, um riso irônico uma explicação sincera ou um silêncio (FIGUEIRÓ, 2013).

Nesse caso, uma das alternativas para trabalhar o tema sexualidade de maneira planejada é a escola com a parceria da família e os profissionais da saúde, pois o corpo em desenvolvimento e as transformaçóes emocionais e sociais parecem que tem contribuído para a maior vulnerabilidade do adolescente, sendo indispensável à presença de um adulto maduro e acolhedor.

Para Aquino (1997), a sexualidade assume o lugar de eixo fundamental da pessoa e a orientação parece tender para a sua utilização imediata assim que ela se 
torna biologicamente disponível. Obstruí-la adquire o caráter de uma violência equivalente à de impedir o exercício de qualquer possibilidade nova, como o andar, pensar, falar. O autor nos revela o quanto é importante a discussão sobre a sexualidade e a reflexão sobre os assuntos que afligem os adolescentes, pois ela resulta em um dos elementos que compóem a identidade pessoal.

Segundo Figueiró (2013), é essecial o adolescente adquirir informações acerca de sua sexualidade ao longo do seu desenvolvimento, pois sua vida se tornaria mais prazerosa e consequentemente o modo de enxergá-la seria melhor, visto que a educação sexual para a autora está baseada na ligação estabelecida entre o sexo e a afetividade.

Portanto, compreender a sexualidade e a educaçáo sexual a partir da percepção dos adolescentes é relevante.

\section{Metodologia}

A metodologia utilizada na análise dos dados dessa pesquisa é quantitativaqualitativa. A pesquisa qualitativa trabalha com o universo dos significados, motivos, aspiraçóes, valores e atitudes. E a quantitativa visa descrever e explicar fenômenos que produzem regularidades. Esses dois tipos de abordagem se bem trabalhada produz riqueza de informaçóes, aprofundamento e fidedignidade interpretativa (MINAYO, 2011).

O instrumento de coleta de dados se constitui de questionário com perguntas fechadas e abertas, tendo participado dela 30 alunos com idades entre 16 a 18 anos, cursando o terceiro ano do ensino médio em escolas públicas e alunos do Cursinho Pré - Vestibular Gratuito do Grupo Pró-Estudar, localizada na cidade de Matão, SP no ano de 2013.

Na primeira etapa o responsável pelo cursinho autorizou a realização da pesquisa com os alunos, no segundo momento, os alunos foram convidados a participarem da pesquisa sobre sexualidade e educação sexual pessoalmente e aqueles que aceitaram responderam ao questionário 5 .

\section{Resultados e discussão}

Os participantes são 10 do gênero masculino, 08 solteiros e $02 \mathrm{em} \mathrm{um}$ relacionamento sério; e 20 do gênero feminino, 15 solteiras e 05 em uma relação séria. Sobre religião $60 \%$ do gênero masculino e $70 \%$ do feminino se declararam cristáos.

5 Algumas questôes do questionário foram baseadas em perguntas disponíveis no site Aventura Social. Disponível em: <http://aventurasocial.com/2005/main.php>. Acesso em: 23 maio 2013. 
A primeira questão buscou saber se os participantes conhecem ou náo o termo educaçáo sexual. Pode-se constatar que $80 \%$ do gênero masculino e $90 \%$ do gênero feminino conhecem o termo educação sexual.

Gráfico 1 - Conhecem ou não o termo educação sexual

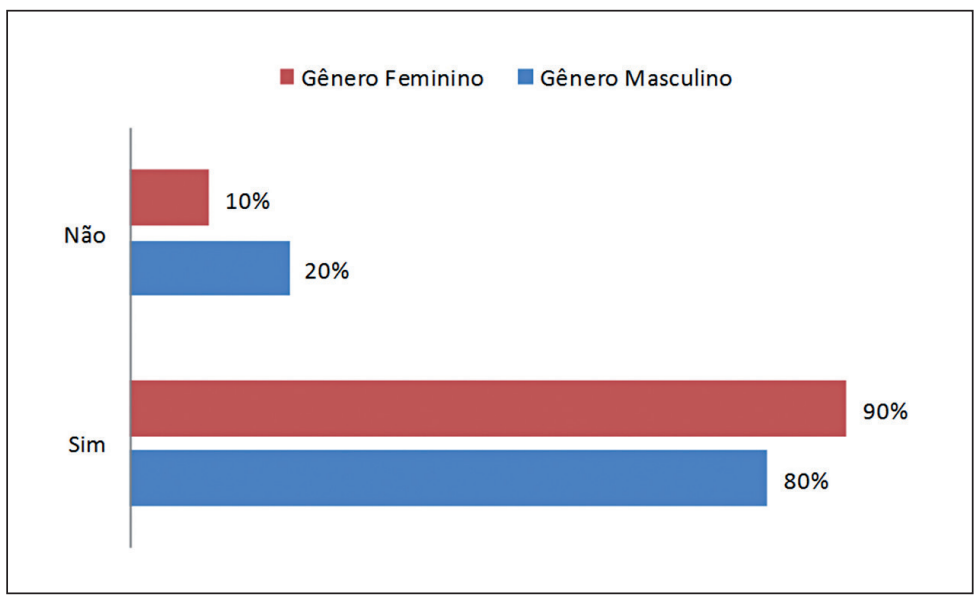

Fonte: Dados da pesquisa.

Quando questionados se eles consideram a educação sexual importante, $100 \%$ relataram que sim. No entanto, apenas $30 \%$ do gênero masculino e $15 \%$ do gênero feminino responderam que participaram de algum projeto sobre educaçáo sexual, sendo $20 \%$ no contexto escolar, o que representa uma pequena parcela de alunos, pois educar sexualmente está interligado ao desenvolvimento sexual saudável dos indivíduos.

A educação sexual consiste no direito de toda pessoa de receber informações referentes ao corpo, sexualidade e relacionamento sexual. E no espaço escolar ensinar sobre sexualidade envolve náo apenas as práticas de ensino, mas a atitude do educador, pois a sexualidade faz parte de nós, ou seja, educar sexualmente possibilita ao outro vivenciar com prazer sua sexualidade (FIGUEIRÓ, 2006).

Maia e Ribeiro (2011) reforçam essa concepção e a ideia que a educação sexual na escola propicia aos alunos informaçóes e reflexóes sobre esses valores por meio das referências culturais e éticas que visam à cidadania ativa e o combate ao preconceito.

Os Parâmetros Curriculares Nacionais (BRASIL, 1998, p.311) inserem a orientação sexual nas escolas por meio dos temas transversais e os objetivos gerais compreendem que "[...] a finalidade do trabalho de Orientação Sexual é contribuir para que os alunos possam desenvolver e exercer sua sexualidade com prazer e responsabilidade [...]". 
Os participantes também descreveram o que compreendem por educaçáo sexual. Observa-se que educação sexual corresponde às questóes relacionadas à prevenção de doenças sexualmente transmissíveis, a orientação sexual, a sanar as dúvidas sobre a temática e, por conseguinte, compreender os constrangimentos que os cercam e como lidar com preconceitos. As falas ressaltam a necessidade de uma educação sexual informativa que os proporcione esclarecimentos acerca das questóes que os permeiam.

São as diversas formas de amor que existe, as relaçóes de sexos diferentes ou iguais. (16 anos).

É a conscientização dos riscos que o sexo traz e a prevenção para estes. (17 anos).

Uma forma de tentar lidar com o problema e o constrangimento das pessoas em relaçâo ao tema, sexo. (18 anos).

É orientar qualquer pessoa sobre a sexualidade, tirando suas dúvidas e questionamentos referente a tal tema. (17 anos).

Educação sexual seria o conhecimento e o aprendizado de assuntos relacionados à sexualidade em geral. É muito importante, principalmente nesse momento da sociedade que há uma precocidade. (17 anos).

Em relação ao gênero feminino (85\%), elas descreveram que educação sexual está relacionada às abordagens no contexto mais amplo, ou seja, a reflexão, a crítica e a informação, como destacadas abaixo.

O conhecimento sobre assuntos sexuais é o maior aprendizado sobre esse assunto que é desconfortável para muitos. (17 anos).

O conhecimento (e autoconhecimento) em relaçáo à sexualidade. (16 anos).

É uma orientação, uma preparação com informaçôes e experiências, passadas aos outros. (17 anos).

A partir do momento que a criança vira pré-adolescente ela deve ter e adquirir com o tempo conhecimentos sobre sexualidade, para com o tempo ter uma boa formaçáo a respeito da sexualidade tendo mais conhecimento do mundo, da sexualidade. (17 anos).

$\mathrm{Na}$ maioria das falas encontram-se aspectos relacionados à orientação sobre os métodos contraceptivos correspondentes à educação sexual de caráter informativo, como destacados nas seguintes explicaçôes.

É um ensino orientação com o objetivo de tornar principalmente os jovens responsáveis pelos seus atos, evitando gravidez precose, doenças etc. (17 anos). 
Ensinamentos sobre a sexualidade, de métodos contraceptivos, se informar sobre a gravidez, sobre doenças sexualmente transmissiveis. (16 anos).

Se trata de dar orientaçôes às pessoas sobre uma vida sexual "saudável". (16 anos).

Educação sexual pra mim é o ensino sobre a sexualidade, envolvendo desde doenças sexualmente transmissiveis, métodos contraceptivos até opção sexual. (17 anos).

É ter informação sobre os cuidades que se deve haver na relação sexual. (17 anos).

Uma jovem relatou outro aspecto importante, a orientação sexual, que nos remete as questóes reflexivas sobre a sexualidade. Em suas palavras "orientaçáo de escolher sua opção sexual seja homem ou mulher, além de ajudar nos modos de proteção, prevençâo" (17 anos). E uma única adolescente não relatou o que é educação sexual, pois não conhece muito sobre o assunto.

Nesse tocante, Maia (2001) expõe que o processo de educação sexual é construído socialmente ao longo da vida e a partir dele que escolhemos e vivemos nossa sexualidade. Furlani (2009) diz que a sexualidade se manifesta desde a infância até a terceira idade, e ressalta que abordar a sexualidade apenas na adolescência reflete uma visão pedagógica limitada, baseada na crença de que a "iniciação sexual" é possível somente a partir da capacidade reprodutiva. Nesse sentido, é importante educar sexualmente desde a tenra idade, sempre refletindo e buscando as informaçóes sobre as questôes relacionadas ao tema e a compreensão da criança.

Os participantes responderam sobre quem os auxilia na educaçáo sexual e as seguintes respostas foram encontradas, entre o público masculino, os pais foram citados com maior frequência, em relaçáo aos professores e amigos. Assim, pode-se considerar que esses adolescentes se sentem mais confiantes e/ou à vontade para conversarem com seus pais. E entre o público feminino, houve equilíbrio nas respostas, nos revelando que para elas tanto os pais, professores e amigos participam do processo de educação sexual. 
Gráfico 2 - Pessoas que auxiliam na educação sexual

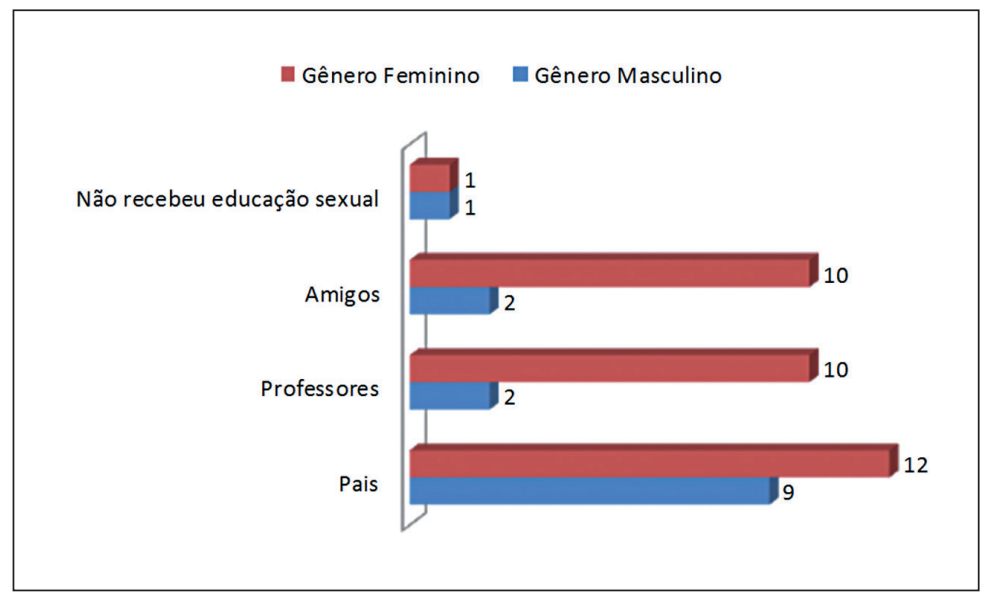

Fonte: Dados da pesquisa

Outro dado interessante é que um aluno e uma aluna responderam que não receberam educação sexual, no entanto, desde o nascimento a família nos transmite o que é ou não correto por meio dos comportamentos ou das falas.

Diante disso, como esses adolescentes se sentem ao falar de educaçáo sexual, os dados estão no Gráfico 3.

Gráfico 3 - Com quem se sentem a vontade para falar sobre sexualidade

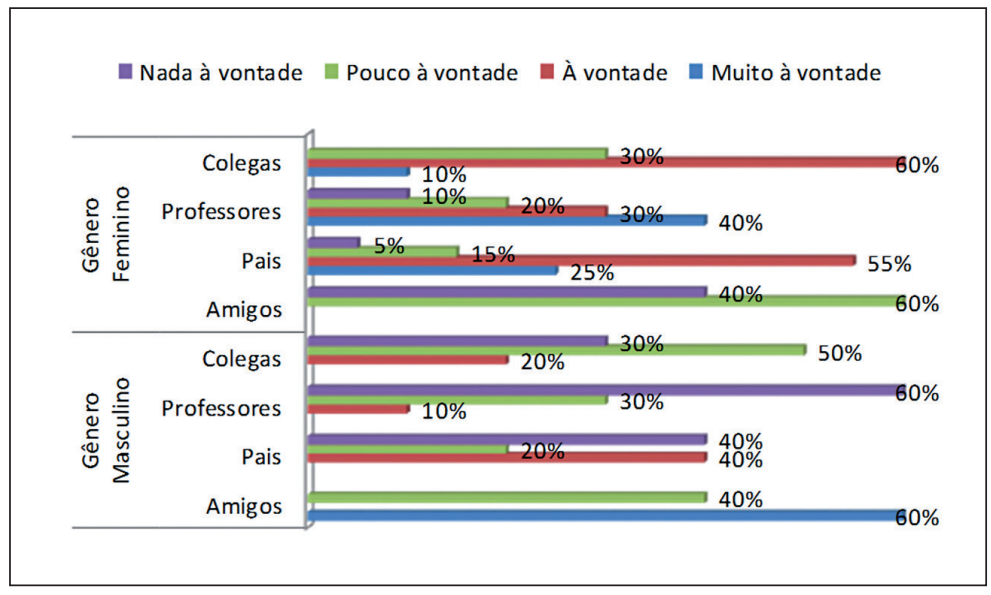

Fonte: Dados da pesquisa 
Como se nota acima, o gênero masculino se sente mais a vontade para falar sobre sexualidade com os amigos em relação aos colegas, professores e pais. $\mathrm{E}$ as adolescentes com os pais do que com os colegas, os professores e amigos.

Segundo Werebe (1998) a educação sexual informal engloba toda a ação exercida sobre o indivíduo no dia a dia desde o nascimento e repercute direta ou indiretamente sobre a vida sexual dele; e a educação sexual formal é institucionalizada e feita dentro ou fora da escola.

Lorencini Júnior (1997) diz que ao longo da vida no processo continuo de busca dos sentidos da sexualidade a pessoa sofre influências diretas da "cultura da sexualidade". Essas influências são provenientes da família, meios de comunicação, religião ou da escola que pressionam, exigem e moldam a pessoa para se adaptar aos padrốes de comportamento impostos pela sociedade.

Portanto, como afirma Pocovi (1998, p.145) "[...] o jovem procura sempre, para conversar, pessoas em quem realmente confia, e não pessoas que tenham a intenção de normatizar seu comportamento, de lhe dar conselhos ou até de querer brincar com seus sentimentos.”

A seguir no Gráfico 4 estão as respostas dos participantes sobre quais os temas sobre sexualidade que eles têm interesse em conhecer melhor.

Gráfico 4 - Temáticas sobre sexualidade

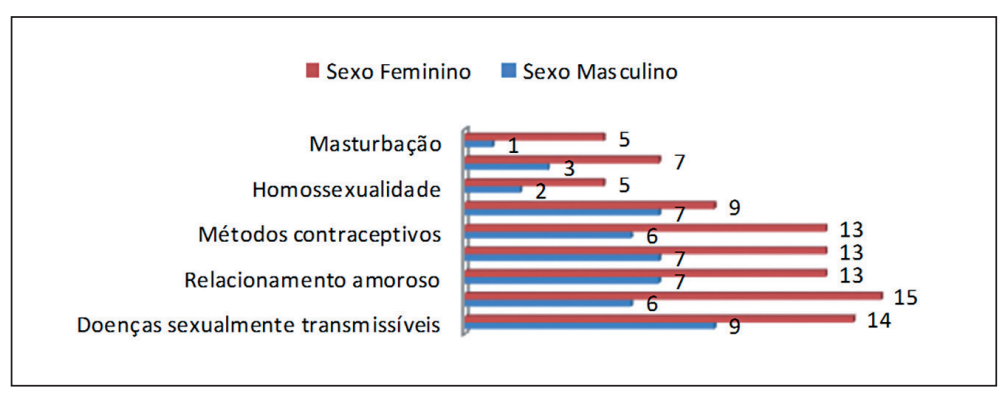

Fonte: Dados da pesquisa

Observa-se que jovens têm de modo geral dúvidas e gostariam de conhecer melhor alguns temas comuns como demonstrado pela quantidade de vezes destacadas em alguns conteúdos. O tema doenças sexualmente transmissíveis apareceu com frequência como interesse de ambos os sexos, mas a preocupação sobre o corpo e gravidez apareceu em maior quantidade nas citaçôes do gênero feminino.

Esses dados ressaltam que a educação sexual no contexto escolar contribui para esclarecer dúvidas e informar os adolescentes a respeito de uma sexualidade positiva e com responsabilidade. É importante levantar com os alunos 
seus interesses e a partir desses dados estruturarem o trabalho de acordo com os temas.

De acordo com os PCN os temas a serem abordados se organizam em três blocos e são eles o corpo, matriz da sexualidade; relaçóes de gênero e prevenção às Doenças Sexualmente Transmissíveis/AIDS (BRASIL,1998). No que diz respeito à seleção e sequência dos temas, Peres et al. (2000) ressaltam que o ideal é não ter uma programação fechada dos temas, pois é sempre mais produtivo organizar a partir do levantamento do grupo.

Egypto (1985) oferece outra contribuição, quando diz que embora seja muito importante trabalhar a partir de temas dos interesses dos educandos, há temas que são indispensáveis e que os educadores precisam abordá-los, mesmo que não solicitados.

Os adolescentes também responderam se tiveram ou não relação sexual, e as seguintes respostas foram encontradas, $20 \%$ do gênero masculino e $25 \%$ gênero feminino tiveram a primeira experiência sexual. Neste sentido, 100\% deles disseram que utilizaram métodos contraceptivos, ou seja, 02 meninos citaram preservativos e entre as meninas 05 citaram o preservativo e 03 delas o anticoncepcional.

Doescher et al. (2012) em pesquisa realizada com 83 adolescentes escolares de ambos os gêneros com idade entre 13 e 17 anos concluíram que é elevado o número de adolescentes que fizeram uso de preservativo na iniciação sexual e dentre aqueles que não a iniciaram disseram que pretendiam utilizá-lo.

Perante as respostas apresentadas, se constata que, a minoria dos adolescentes vivenciou um relacionamento sério e iniciou a vida sexual, mas eles estão se prevenindo de uma possível gravidez indesejada, de contrair doenças sexualmente transmissíveis e se tornarem pais ainda jovens; ou seja, é um fator relevante e importante a ser destacado.

Em relação às preocupaçóes, cuidados e prevenção, os adolescentes responderam se eles têm alguma preocupação em relação à sexualidade, $60 \%$ do sexo masculino responderam não, $30 \%$ que sim e $10 \%$ não responderam nenhuma alternativa. Apenas 01 dos 03 alunos que responderam sim, disse que: "é preocupante, apesar de ser um ato que propoporciou prazer deixa sempre uma preocupação."

Das jovens do sexo feminino, $50 \%$ responderam que não se preocupam, $40 \%$ que se preocupam e $10 \%$ não responderam a questão. Dentre os $40 \%$ que se preocupam, os seguintes itens foram citados: "gravidez"(02), "modos de obter uma relação prazeirosa e saudável" (01), "com os cuidados que se deve tomar"(01), "os cuidados que devem existir" (01), "doenças sexualmente transmissiveis"(01), "saber a hora certa" (01), "métodos mais eficientes" (01), "acho que as próprias da idade" (01) $e$ "existe preocupação, mas não dúvidas em relação a condição sexual"(01). 
Acima, apesar da maioria negar que se preocupar com a sexualidade, os que responderam positivamente a questão, reforçam os dados sobre os temas que eles gostariam de conhecer mais, principalmente em relação ao prazer, as doenças, a prevenção e ao momento certo para ter a relaçáo sexual que são próprios da idade.

Por conseguinte, em algumas frases os adolescentes colocaram o grau de concordância e discordância sobre a questão dos preservativos e os seguintes resultados foram obtidos, para $40 \%$ dos adolescentes do sexo masculino, não seria desconfortável comprar preservativos numa loja, 20\% concorda que seria desconfortável e $40 \%$ não concorda nem discorda. Na concepção das adolescentes do gênero feminino, $5 \%$ discordaram completamente, $25 \%$ não concordaram, nem discordaram, $60 \%$ concordaram e $10 \%$ concordaram completamente com a frase, seria desconfortável comprar preservativos numa loja.

Em relação à frase, seria desconfortável trazer contigo preservativos, as seguintes respostas foram encontradas e sistematizadas no Gráfico 5.

Gráfico 5 - Desconfortável trazer contigo preservativos

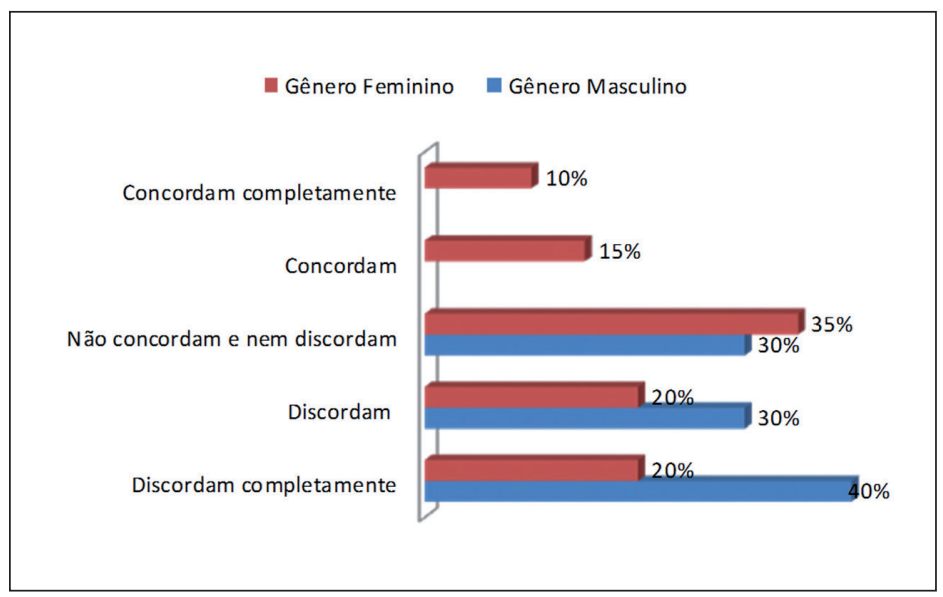

Fonte: Dados da pesquisa

Para eles, trazer um preservativo significa que estás a planejar ter relaçóes sexuais, $20 \%$ discordaram completamente, $40 \%$ discordaram, 30\% náo concordaram nem discordaram e $10 \%$ concordam. Elas responderam que trazer um preservativo contigo significa que estás a planejar ter relaçóes sexuais, 15\% discordaram completamente, $40 \%$ discordaram, $40 \%$ não concordaram nem discordaram e $5 \%$ concordaram.

$\mathrm{Na}$ última frase, seria desconfortável adquirir preservativos no centro de saúde, para eles, $10 \%$ discordaram completamente, $40 \%$ discordaram, $40 \%$ não concordaram nem discordaram e 10\% concordaram completamente. 
Para elas, 5\% discordaram completamente, 5\%, discordaram, 30\% não concordaram nem discordaram, $40 \%$ concordaram e $20 \%$ concordaram completamente.

Portanto, para os jovens do sexo masculino comprar preservativos não seria desconfortável, diferente da visão feminina que considera desconfortável realizar a compra em uma loja. No entanto, tanto para o sexo masculino quanto para o feminino possuir preservativos não seria desconfortável, assim como para a maioria dos jovens do sexo masculino e feminino possuir preservativo náo significa que estão planejando ter relaçóes sexuais. No entanto, adquirir preservativos no centro de saúde náo seria desconfortável para o sexo masculino, mas seria desconfortável para a maioria das jovens do sexo feminino.

E como o sexo masculino se sentiria nas seguintes situaçóes, conversar com o parceiro/a sexual sobre o uso do preservativo, $20 \%$ pouco à vontade, $60 \%$ à vontade e $20 \%$ muito à vontade; convencer um/a parceiro/a sexual a usar preservativo, $20 \%$ pouco à vontade, $40 \%$ à vontade, $20 \%$ muito à vontade e $20 \%$ não sabem; recusar ter relaçôes sexuais sem usar preservativo, se o/a parceiro/a não quisesse usar, $10 \%$ náo me sinto capaz, $40 \%$ à vontade, $20 \%$ muito à vontade e 30\% não sabem; recusares-te a ter relações sexuais se não quiseres, $10 \%$ não me sinto capaz, $10 \%$ pouco à vontade, $20 \%$ à vontade, $10 \%$ muito à vontade $\mathrm{e}$ $50 \%$ não sabem.

Para as adolescentes do sexo feminino, conversar com o teu parceiro/a sexual sobre o uso do preservativo, $5 \%$ pouco à vontade, $50 \%$ à vontade, $35 \%$ muito à vontade e $10 \%$ náo sabem; convencer um/a parceiro/a sexual a usar preservativo, $5 \%$ náo me sinto capaz, $45 \%$ àvontade, $35 \%$ muito à vontade e $15 \%$ não sabem; recusar ter relações sexuais sem usar preservativo, se o/a parceiro/a não quisesse usar, 5\% não me sinto capaz, 5\% pouco à vontade, $20 \%$ à vontade, $65 \%$ muito à vontade e $5 \%$ não sabem; recusares-te a ter relaçóes sexuais se náo quiseres, $5 \%$ não me sinto capaz, $20 \%$ à vontade, $65 \%$ muito à vontade e $10 \%$ não sabem.

Esses dados demostram que a maioria dos adolescentes se sentem à vontade para conversar sobre o uso de preservativo com o/a parceiro/a sexual, assim como as garotas. No tocante, a convencer um/a parceiro/a sexual a usar preservativo, para maioria dos alunos do sexo masculino não teriam problemas e/ou dificuldades, da mesma forma para as alunas do sexo feminino. Outro aspecto importante é que para a maior parte dos jovens do sexo masculino e do sexo feminino se sentem à vontade para conversar com o/a parceiro/a caso este/a quisesse ter relaçóes sexuais sem usar preservativo. Isto demonstra que os/ as jovens estão se prevenindo contra doenças sexualmente transmissíveis ou uma possível gravidez. Mas, quando se trata em recusar a ter relaçóes sexuais se não 
quiserem, os jovens do sexo masculino ficaram divididos entre não saberem o que fazer $(50 \%)$ ou não se sentirem à vontade $(20 \%)$ e apenas $30 \%$ se sentem a vontade para recusarem. Diferente da maioria das garotas que se sentem capaz de recusar um pedido caso não queiram.

\section{Considerações finais}

A adolescência é um período importante na qual o jovem deixa de ser criança para tornar-se adulto. Neste momento muitas dúvidas e questionamentos são levantados, principalmente relacionadas às questóes da sexualidade. A partir deste estudo, compreende-se que a maioria dos adolescentes conhece o termo educação sexual, mas não teve contato com profissionais que transmitissem formalmente os assuntos relacionados a ela para sanar as inúmeras interrogaçóes que permeiam suas existências e estão em grande parte relacionadas aos aspectos biológicos e de prevenção.

Outra característica é que para os adolescentes do gênero masculino conversam sobre sexualidade com maior frequência entre os amigos, diferentemente das garotas que conversam tanto com os pais. Destaca-se também que a minoria está em um relacionamento sério, o namoro e já tiveram relação sexual. Contudo, estes jovens que já tiveram esta experiência estão se prevenindo, o que aponta para uma reflexão perante as consequências que uma doença transmitida sexualmente ou uma gravidez precoce ou indesejada acarretaria nas vidas desses adolescentes.

Portanto, a educação sexual é fundamental para todos os indivíduos, pois proporciona a compreensáo dos seus corpos, das suas relaçóes afetivas e sexuais na busca da quebra de discursos preconceituosos e no conhecimento de suas sexualidades.

\section{REFERÊNCIAS}

AQUINO, J. G. (Org.). Sexualidade na escola: alternativas teóricas e práticas. São Paulo: Summus, 1997.

BRASIL. Ministério da Educaçáo. Secretaria de Educação Fundamental. Parâmetros curriculares nacionais: terceiro e quarto ciclos do ensino fundamental: introduçáo aos parâmetros curriculares nacionais. Brasília, 1998.

DOESCHER, A. M. L. et al. Analisando o comportamento sexual de risco: o conhecimento dos métodos contraceptivos pelos adolescentes. In: SOUZA, L. L. de; SALGADO, R. G. (Org.). Infância e juventude no contexto brasileiro: gêneros e sexualidade em debate. Cuiabá: Ed. da UFMT, 2012. v.1, p.133-153.

EGYPTO, A. C. À guisa de conclusão. In: BARROSO, C.; BRUSCHINI, C. Sexo e juventude: como discutir sexualidade em casa e na escola. 2.ed. São Paulo: Cortez, 1985. p.79-82. 
FIERRO, A. Desenvolvimento da personalidade na adolescência. In: COLL, C.; PALACIOS, J.; MARCHESI, A. Desenvolvimento psicológico e educaçáo: psicologia evolutiva. Porto Alegre: ARTMED, 1995. v.1, p.288-298.

FIGUEIRÓ, M. N. D. Educaçáo sexual no dia a dia. Londrina: EDUEL, 2013.

. Educação sexual: como ensinar no espaço da escola. Revista Linhas, Florianópolis, v.7, n.1, p.01-21, 2006. Disponível em: <http://www.periodicos.udesc.br/index.php/linhas/ article/viewFile/1323/1132>. Acesso em: 18 mar. 2013.

FURLANI, J. Encarar o desafio da Educaçáo Sexual na escola. In: Secretaria de Estado da Educação. Superintendência de Educação. Departamento de Diversidades. Núcleo de Gênero e Diversidade Sexual. Sexualidade. Curitiba: SEED, 2009. p.37-48.

LORENCINI JÚNIOR, A. Os sentidos da sexualidade: natureza, cultura e educaçáo. In: AQUINO, J. G. (Org.). Sexualidade na escola: alternativas teóricas e práticas. São Paulo: Summus, 1997. p.87-95.

MAIA, A. C. B. Reflexóes sobre a educaçáo sexual da pessoa com deficiência. Revista brasileira de Educaçáo Especial, São Paulo, v.07, n.01, p.35-46, 2001. Disponível em: <http://educa.fcc.org.br/pdf/rbee/v07n01/v07n01a04.pdf>. Acesso em: 18 mar. 2013.

MAIA, A. C. B.; RIBEIRO, P. R. M. Educação sexual: princípios para ação. Doxa: Revista Brasileira de Psicologia e Educaçáo, Araraquara, v.15, n.1, p.75-84, 2011.

MINAYO, M. C. S. O desafio da pesquisa social. In: MINAYO, M. C. S. et al. Pesquisa social: teoria, método e criatividade. 30.ed. Petrópolis: Vozes, 2011. p.9-30.

PACHECO, M. E. M. S. Caracterização do adolescente. In: VITALLE, M. S. S.; MEDEIROS, E. H. G. R. (Coord.). Adolescência: uma abordagem ambulatorial. Barueri: Manole, 2008. p.9-16.

POCOVI, R. M. Contribuiçôes de Rousseau aos pais e educadores de hoje na questão da Educação Sexual. Perspectiva: Sexualidade e Educaçáo, Florianópolis, v.17, n.3, p.143151, dez. 1998.

PERES, C. A. et al. Fala educadora! Educador! São Paulo: Organon, [2000?].

WEREBE, M. J. G. Sexualidade, política e educação. Campinas: Autores Associados, 1998. 


\title{
Resumo
}

\section{Percepçōes de adolescentes sobre sexualidade e educação sexual}

Falar em sexualidade com adolescentes nem sempre é uma tarefa fácil, mas extremamente necessária, além de tema transversal em educação. Esta pesquisa tem por objetivo analisar as respostas obtidas com a aplicação de um questionário aos alunos de Ensino Médio de escolas públicas que frequentam cursinho pré-vestibular comunitário na t de Matáo/SP. Os resultados mostraram que os adolescentes conhecem o termo educaçáo sexual, no entanto a maioria deles nunca participaram de projetos sobre a temática. As dúvidas estáo relacionadas aos aspectos biológicos e de prevençáo. O gênero masculino se sente a vontade para conversar sobre sexualidade com os amigos e o gênero feminino com os pais. Sendo assim, percebese a carência de contato com profissionais em educaçáo sexual desses adolescentes e a predominância de discursos biológicos e de prevenção de doenças.

Palavras-chave: Sexualidade. Educação sexual. Adolescência.

\begin{abstract}
Perceptions of teenagers on sexuality and sex education

Speaking of sexuality with teenagers is not always an easy task, but extremely necessary, as well as cross-cutting theme in education. This research aims to analyze the responses obtained with the application of a questionnaire to students of secondary education in public schools who attend Community pre-university preparatory course in the city of Matão / SP. The results showed that adolescents know the term sex education, but most of them never participated in projects on the subject. The doubts are related to the biological aspects and prevention. And the male feels comfortable talking about sexuality with friends and the females with their parents. Thus, we see the lack of contact with professionals in sexual education of these adolescents and the prevalence of biological speeches and disease prevention.
\end{abstract}

Keywords: Sexuality. Sex education. Adolescence 